\title{
Ultrasonic Wave Propagation in Californium Monopnictides
}

\author{
Rajkumar $^{1, *}$, Devraj Singh ${ }^{2}$ and Giridhar Mishra ${ }^{2}$ \\ ${ }^{1}$ Department of Physics, Nims University, Jaipur, India \\ ${ }^{2}$ Department of Applied Physics, Amity School of Engineering and Technology, Bijwasan, New Delhi, India \\ *E-mail:rajkiit@rediffmail.com
}

Received November 12, 2011; revised December 15, 2011; accepted December 30, 2011

\begin{abstract}
In this paper, theoretical computations have been made for the investigations of temperature dependence of the ultrasonic parameters like ultrasonic velocities and Grüneisen parameters in californium monopnictides $\mathrm{CfY}$ (Y: N, As and Sb) for longitudinal and shear waves along $<100>,<110>$ and $<111>$ crystallographic directions in the temperature range $100-500 \mathrm{~K}$. For the same evaluation the second- and third- order elastic constants have also been computed for these monopnictides using Coulomb and Born-Mayer potential upto second nearest neighborhood. The mechanical properties and stability of $\mathrm{CfN}$ is best, because of its high valued elastic constants. Ultrasonic velocity is found to be highest for CfAs along all chosen directions, so CfAs will be most suitable compound for wave propagation. The obtained results of present investigation are discussed in along with identified thermophysical properties.
\end{abstract}

Keywords: Californium monopnictides; Coulomb and Born-Mayer potential; Elastic constants; Ultrasonic velocity; Grüneisen parameters

\section{Introduction}

Ultrasonic non-destructive testing (NDT) is a useful technique that can be applied to a range of materials for the characterization of their microstructures, the appraisal of defects and the determination of physical properties such as density, thermal conductivity and electrical resistivity. The Grüneisen parameter is of considerable importance to Earth's scientists, because it sets limitations on the thermoelastic properties of lower mantle [1]. The study of Grüneisen parameters for a solid enables us to describe and discuss the various physical properties of a system, such as high temperature specific heats of lattice, thermal expansion, thermal conductivity and temperature variation of the elastic constants. The Grüneisen parameters play a significant role in the study of thermoelastic properties. It has its fundamental importance to the equation of state of a system and related thermodynamic properties of the solids [2]. The calculation of anharmonic effects in solids such as thermal expansion or the interaction of acoustic and thermal phonons involves Grüneisen parameters, which describe the volume and strain dependence of the lattice vibrational frequencies. In the Debye model, these vibrations are replaced by standing wave modes of a dispersionless elastic continuum. The Grüneisen parameters are then no longer frequency dependent and can be expressed in terms of second- and third- order elastic constants [3]. Wave velocity is the key parameter in ultrasonic characterization and can provide information about crystallographic texture. The ultrasonic velocity $(\mathrm{V})$ is related to the elastic constant by the relation $\mathrm{V}=\sqrt{ }(\mathrm{C} / \rho)$, where $\mathrm{C}$ is the relevant elastic constant and $\rho$ is the density of that particular material. The elastic constant, in particular provides valuable information on the stability and stiffness of the materials. The elastic constants of solids also provide a link between the mechanical and dynamical behaviours of crystals and give important information concerning the nature of forces operating in solids [4]. To the best of our knowledge, the studies of californium monopnictides have not been found in detail and we hope the ultrasonic study can be of potential interest. We found few studies of californium monopnictides in literature [5-8]. Haire et al. [5] and Damien et al. [6] studied the crystal structure and lattice parameters of $\mathrm{Cf}$ monopnictides and also proved semimetallic nature of CfY. Magnetism of californium Monopnictides has been discussed by Nave et al. [7-8]. No experimental and theoretical result on ultra- 
sonic velocity and Grüneisen parameters on these materials has been found in the literature. Moreover the temperature dependent elastic constants have not been computed and measured, which stimulates us to execute theoretical analysis of elastic constants, ultrasonic velocities and Grüneisen parameters in californium monopnictides along $<100\rangle,<110\rangle$ and $<111>$ directions at temperature range $100 \mathrm{~K}-500 \mathrm{~K}$.

\section{Theory}

The second and third order elastic constants (SOEC and TOEC) have been calculated following Brugger's definition of elastic constants [9-10] at absolute zero $\left(C_{I J}^{0}\right.$ and $C_{I J K}^{0}$ ). The SOEC and TOEC at different higher temperatures are obtained by the method developed by Leibfried and Haln [11], Ludwig [12] and Hiki [13] for NaCl-type crystals as the chosen semimetallics have well-developed structures of the NaCl-type crystals. The lattice parameters are very close to those in literature [6-8,14].

When sound wave propagates through a solid medium, there are three modes of propagation one longitudinal acoustical and two transverse acoustical. Hence, there exist three types of velocities, as one longitudinal $\left(\mathrm{V}_{\mathrm{L}}\right)$ and two shear $\left(\mathrm{V}_{\mathrm{S} 1}\right.$ and $\left.\mathrm{V}_{\mathrm{S} 2}\right)$ that depend on the direction of propagation of wave [15]. The direction dependent ultrasonic velocities for a cubic crystal are expressed as given below

Along $<100>$ crystallographic direction;

$$
\left.\begin{array}{rl}
V_{L} & =\sqrt{\left(C_{11} / \rho\right)} ; \\
\mathrm{V}_{\mathrm{S} 1} & =V_{S 2}=\sqrt{\left(C_{44} / \rho\right)}
\end{array}\right\}
$$

Along $<111>$ crystallographic direction;

$$
\left.\begin{array}{l}
V_{L}=\sqrt{\left(C_{11}+2 C_{12}+4 C_{44}\right) / 3 \rho} ; \\
\mathrm{V}_{\mathrm{S} 1}=V_{S 2}=\sqrt{\sqrt{\left(C_{11}-C_{12}+C_{44}\right) / 3 \rho}}
\end{array}\right\}
$$

Along $<110>$ crystallographic direction;

$$
\left.\begin{array}{l}
V_{L}=\sqrt{\frac{C_{11}+C_{12}+2 C_{44}}{2 \rho}} ; \\
\mathrm{V}_{\mathrm{S} 1}=\sqrt{\frac{C_{44}}{\rho}} ; V_{S 2}=\sqrt{\frac{C_{11}-C_{12}}{\rho}}
\end{array}\right\}
$$

where $\mathrm{C}_{\mathrm{IJ}}$ are particular elastic constant of the material and $\rho$ is the density. The Debye average velocity $\left(V_{D}\right)$ is useful for information of Debye temperature and thermal relaxation time of the materials. The following expressions have been used for evaluation of Debye average velocity [12].

$$
\left.\begin{array}{rl}
V_{m}= & {\left[\frac{1}{3}\left\{\frac{1}{V_{L}^{3}}+\frac{2}{V_{S 1}^{3}}\right\}\right]^{-1 / 3} ;} \\
& \text { along }<100>,<111>\text { directions } \\
= & {\left[\frac{1}{3}\left\{\frac{1}{V_{L}^{3}}+\frac{1}{V_{S 1}^{3}}+\frac{1}{V_{S 2}^{3}}\right\}\right]^{-1 / 3} ;} \\
& \text { along }<110>\text { direction }
\end{array}\right\}
$$

A number of anharmonic properties of solids are frequently expressed in terms of Grüneisen parameters, which are expressed, in quasiharmonic approximation, as diverse weighted averages of Grüneisen tensor of the first order: $\gamma_{\alpha \beta}^{j}=-\omega_{i}^{-1} \partial \omega_{i}(q) / \partial \eta_{\alpha \beta}$. For example, the thermal expansivity is relative to the specific heat weighted $\left\langle\gamma_{\alpha \beta}\right\rangle=\sum_{q, i} C_{q, i} \gamma_{\alpha \beta}^{j} \sum_{q, i} C_{q, i}$,which is thermal Grüneisen parameters $\gamma$; and the (shear) ultrasonic attenuation's Grüneisen parameter can be suitably expressed [16] by thermal conductivity weighted averages of the product $\gamma_{\alpha \beta}^{j} \gamma_{\gamma \delta}^{j}$. Brugger [17] derived expressions for the components of Grüneisen tensor in terms of SOEC and TOEC of an anisotropic elastic continuum. These relations permit the above weighted average to be reliably calculated from elastic and thermal data to give ultrasonic attenuation and non-linear parameters, which compares very well with measured results [18]. Formulae of Grüneisen parameters along different crystallographic directions are given in literature [19].

\section{Results and Discussion}

The elastic constants of materials are directly related to their microstructure and are used to obtain the Debye average velocity, Grüneisen parameter and other physical properties; and therefore, these are of great interest in applications where the mechanical strength and durability are important. The SOEC and TOEC have been evaluated using two basic parameters i.e., lattice parameter and hardness parameter. The lattice parameters $[6$, 7, 14] for CfN, CfAs and CfSb are $4.95 \AA, 5.809 \AA$, and $6.165 \AA$ and the value of hardness parameters [20] are $0.313 \AA, 0.303 \AA$ and $0.311 \AA$ respectively. The computed results of temperature dependent SOEC and TOEC are given in Tables 1. No experimental/theoretical result of SOEC and TOEC of these materials was found directly in existing literature. So our achieved results have been compared with gadolinium monopnictides GdY [21]. These compared results are available in Table 1. It is clear from Table 1 that out of nine elastic constants, four (i.e., $\mathrm{C}_{11}, \mathrm{C}_{44}, \mathrm{C}_{112}$ and $\mathrm{C}_{144}$ ) are increasing and four (i.e., $\mathrm{C}_{12}, \mathrm{C}_{111}, \mathrm{C}_{166}$ and $\mathrm{C}_{123}$ ) are decreasing with the temperature while $\mathrm{C}_{456}$ is found to be unaffected. This trend of elastic constants in chosen materials at higher 
Table 1. Second and third order elastic constants of CfY at the temperature range 100 to $500 \mathrm{~K}$ with comparable data of GdY at room temperature [in the unit of $10^{11}$ Dyne/ $\mathrm{cm}^{2}$ ].

\begin{tabular}{|c|c|c|c|c|c|c|c|c|c|c|}
\hline Material & Temp (K) & $\mathrm{C}_{11}$ & $\mathrm{C}_{12}$ & $\mathrm{C}_{44}$ & $\mathrm{C}_{111}$ & $\mathrm{C}_{112}$ & $\mathrm{C}_{123}$ & $\mathrm{C}_{144}$ & $\mathrm{C}_{166}$ & $\mathrm{C}_{456}$ \\
\hline \multirow{5}{*}{$\mathrm{CfN}$} & 100 & 6.15 & 2.58 & 2.68 & -90.42 & -10.66 & 3.77 & 4.20 & -11.00 & 4.17 \\
\hline & 200 & 6.29 & 2.50 & 2.69 & -90.76 & -10.41 & 3.37 & 4.23 & -11.03 & 4.17 \\
\hline & 300 & 6.46 & 2.42 & 2.70 & -91.42 & -10.15 & 2.98 & 4.26 & -11.07 & 4.17 \\
\hline & 400 & 6.65 & 2.33 & 2.71 & -92.19 & -9.886 & 2.58 & 4.28 & -11.11 & 4.17 \\
\hline & 500 & 6.84 & 2.25 & 2.72 & -93.01 & -9.623 & 2.18 & 4.31 & -11.15 & 4.17 \\
\hline \multirow{5}{*}{ CfAs } & 100 & 4.96 & 1.22 & 1.30 & -81.57 & -4.97 & 1.71 & 2.21 & -5.30 & 2.20 \\
\hline & 200 & 5.13 & 1.14 & 1.31 & -82.40 & -4.66 & 1.23 & 2.23 & -5.33 & 2.20 \\
\hline & 300 & 5.37 & 1.06 & 1.31 & -84.03 & -4.35 & 0.75 & 2.25 & -5.36 & 2.20 \\
\hline & 400 & 5.49 & 0.98 & 1.32 & -84.28 & -4.04 & 0.26 & 2.26 & -5.37 & $2 . .20$ \\
\hline & 500 & 5.68 & 0.90 & 1.32 & -85.25 & -3.72 & -0.21 & 2.28 & -5.40 & 2.20 \\
\hline \multirow{5}{*}{$\mathrm{CfSb}$} & 100 & 4.17 & 0.94 & 1.01 & -69.96 & -3.79 & 1.27 & 1.74 & -4.10 & 1.73 \\
\hline & 200 & 4.33 & 0.86 & 1.02 & -70.78 & -3.50 & 0.82 & 1.75 & -4.12 & 1.73 \\
\hline & 300 & 4.49 & 0.79 & 1.02 & -71.65 & -3.21 & 0.37 & 1.77 & -4.14 & 1.73 \\
\hline & 400 & 4.66 & 0.72 & 1.02 & -72.54 & -2.92 & -0.07 & 1.78 & -4.16 & 1.73 \\
\hline & 500 & 4.82 & 0.06 & 1.03 & -73.43 & -2.63 & 0.05 & 1.79 & -4.18 & 1.73 \\
\hline $\mathrm{GdP}[22]$ & 300 & 5.54 & 1.16 & 1.43 & -86.17 & -4.76 & 0.90 & 2.41 & -5.78 & 2.36 \\
\hline GdAs[22] & 300 & 5.29 & 1.03 & 1.28 & -83.30 & -4.18 & 0.67 & 2.19 & -5.19 & 2.14 \\
\hline $\mathrm{GdSb}[22]$ & 300 & 4.68 & 0.74 & 0.98 & -76.17 & -2.92 & 0.17 & 1.17 & -3.93 & 1.67 \\
\hline GdBi[22] & 300 & 4.60 & 0.69 & 0.96 & -74.78 & -2.71 & 0.09 & 1.63 & -3.72 & 1.60 \\
\hline
\end{tabular}

temperatures is due various parameters involved in the expressions used for the evaluation of elastic constants $[6-8,14]$. This type of behaviour has already been found in other $\mathrm{NaCl}$-type materials like gadolinium and cerium monopnictides [21-25]. Hence our approach to find out the elastic constants at different temperatures is justified.

There are no elastic data as a function of temperature for these compounds. Table 1 depicts that CfN has highest valued SOEC and TOEC in contrast to other monopnictides. Hence mechanical properties of CfN are better than those of CfAs and CfSb. According to the Born criterion of a lattice to be stable, the elastic energy density must be positive. The values of bulk moduli $\left(\mathrm{B}_{\mathrm{T}}\right)$, shear moduli $\left(\mathrm{C}_{44}\right)$ and tetragonal moduli $\left(\mathrm{C}_{\mathrm{S}}\right)$ of the chosen materials CfN, CfAs and CfSb are $\mathrm{B}_{\mathrm{T}}=\left(\mathrm{C}_{11}+2 \mathrm{C}_{12}\right) / 3>$ $0, \mathrm{C}_{44}>0$ and $\mathrm{Cs}=\left(\mathrm{C}_{11}-\mathrm{C}_{12}\right) / 2>0$ respectively.

Estimated values of bulk moduli, shear moduli and tetragonal moduli are tabulated in Table 2. The values of bulk moduli $\left(\mathrm{B}_{\mathrm{T}}\right)$, shear moduli $\left(\mathrm{C}_{44}\right)$ and tetragonal moduli $\left(\mathrm{C}_{\mathrm{S}}\right)$ are satisfying the stability criterion for $\mathrm{CfN}$, $\mathrm{CfAs}$ and $\mathrm{CfSb}$ compounds. Hence our approach to find out the elastic constants is correct and reasonable. The ultrasonic velocity is a key factor to characterize the properties of materials. It is directly related to SOEC and density of that particular material as shown in Eqs. (1)-(3) and presented in Table 3.

It can be seen that the velocities of the chosen materials
Table 2. Bulk moduli $\left(B_{T}\right)$ and tetragonal moduli $\left(C_{S}\right)$ of $\mathrm{CfY}$ at room temperature in the unit of $10^{11} \mathrm{Dyne} / \mathrm{cm}^{2}$.

\begin{tabular}{ccc}
\hline Material & $\mathrm{B}_{\mathrm{T}}$ & $\mathrm{C}_{\mathrm{S}}$ \\
\hline $\mathrm{CfN}$ & 3.77 & 1.89 \\
$\mathrm{CfAs}$ & 2.47 & 1.99 \\
$\mathrm{CfSb}$ & 2.01 & 3.23 \\
\hline
\end{tabular}

along longitudinal and shear waves increase with increase in temperature. The Debye average velocity in these materials is highest along $<100>$ direction and lowest along $<110>$ direction and increases with temperature as shown in Figures 1-3. Due to lack of experimental data for ultrasonic velocities of CfY, we have compared our results with other B1 structured materials like semiconductor [23] and rare-earth monopnictides $[21,24]$ and rare-earth monochalcogenides [24,25] and found that the order of ultrasonic velocities and Debye average velocity have the similar nature. It is clear from Figures 1-3, that the computed values of the Debye average ultrasonic velocities are the highest in case of CfAs. So we can say that the propagation of sound waves through CfAs will be better than that of other chosen materials. SOEC and TOEC are used to obtain Grüneisen parameters and average squares of the Grüneisen parameters along $<110>$ direction for longitudinal wave over 36 modes, for shear wave polarized along $<001>$ 
Table 3. Ultrasonic velocities (in $10^{5} \mathrm{~cm} / \mathrm{s}$ ) of $\mathrm{CfY}$ along different crystallographic directions in the temperature range $100 \mathrm{~K}$ - $500 \mathrm{~K}$.

\begin{tabular}{|c|c|c|c|c|c|c|c|}
\hline Materials & Directions & Velocity & $100 \mathrm{~K}$ & $200 \mathrm{~K}$ & $300 \mathrm{~K}$ & $400 \mathrm{~K}$ & $500 \mathrm{~K}$ \\
\hline \multirow{7}{*}{$\mathrm{CfN}$} & \multirow{2}{*}{$<100>$} & $\mathrm{V}_{\mathrm{L}}$ & 2.060 & 2.082 & 2.110 & 2.141 & 2.171 \\
\hline & & $\mathrm{V}_{\mathrm{S} 1}=\mathrm{V}_{\mathrm{S} 2}$ & 1.359 & 1.361 & 1.364 & 1.367 & 1.369 \\
\hline & \multirow{3}{*}{$<111>$} & $\mathrm{V}_{\mathrm{L}}$ & 2.250 & 2.251 & 2.253 & 2.257 & 2.260 \\
\hline & & $\mathrm{V}_{\mathrm{S} 1}=\mathrm{V}_{\mathrm{S} 2}$ & 1.198 & 1.219 & 1.244 & 1.270 & 1.295 \\
\hline & & $\mathrm{V}_{\mathrm{L}}$ & 2.204 & 2.210 & 2.219 & 2.228 & 2.238 \\
\hline & \multirow{3}{*}{$<110>$} & $\mathrm{V}_{\mathrm{S} 1}$ & 1.359 & 1.361 & 1.364 & 1.367 & 1.369 \\
\hline & & $\mathrm{V}_{\mathrm{S} 2}$ & 1.569 & 1.615 & 1.669 & 1.723 & 1.777 \\
\hline \multirow{7}{*}{ CfAs } & & $\mathrm{V}_{\mathrm{L}}$ & 2.088 & 2.124 & 2.174 & 2.198 & 2.234 \\
\hline & \multirow[t]{2}{*}{$<100>$} & $\mathrm{V}_{\mathrm{S} 1}=\mathrm{V}_{\mathrm{S} 2}$ & 1.072 & 1.074 & 1.076 & 1.078 & 1.080 \\
\hline & & $\mathrm{V}_{\mathrm{L}}$ & 1.924 & 1.926 & 1.930 & 1.933 & 1.937 \\
\hline & \multirow{2}{*}{$<111>$} & $\mathrm{V}_{\mathrm{S} 1}=\mathrm{V}_{\mathrm{S} 2}$ & 1.215 & 1.246 & 1.277 & 1.307 & 1.337 \\
\hline & & $\mathrm{V}_{\mathrm{L}}$ & 1.966 & 1.978 & 1.990 & 2.003 & 2.015 \\
\hline & \multirow{2}{*}{$<110>$} & $\mathrm{V}_{\mathrm{S} 1}$ & 1.072 & 1.074 & 1.076 & 1.078 & 1.080 \\
\hline & & $\mathrm{V}_{\mathrm{S} 2}$ & 1.812 & 1.872 & 1.946 & 1.991 & 2.048 \\
\hline \multirow{7}{*}{$\mathrm{CfSb}$} & \multirow{2}{*}{$<100>$} & $\mathrm{V}_{\mathrm{L}}$ & 1.988 & 2.026 & 2.064 & 2.101 & 2.138 \\
\hline & & $\mathrm{V}_{\mathrm{S} 1}=\mathrm{V}_{\mathrm{S} 2}$ & 0.981 & 0.983 & 0.985 & 0.987 & 0.989 \\
\hline & \multirow{2}{*}{$<111>$} & $\mathrm{V}_{\mathrm{L}}$ & 1.787 & 1.790 & 1.793 & 1.797 & 1.800 \\
\hline & & $\mathrm{V}_{\mathrm{S} 1}=\mathrm{V}_{\mathrm{S} 2}$ & 1.158 & 1.190 & 1.221 & 1.251 & 1.281 \\
\hline & \multirow{3}{*}{$<110>$} & $\mathrm{V}_{\mathrm{L}}$ & 1.840 & 1.852 & 1.865 & 1.877 & 1.890 \\
\hline & & $\mathrm{V}_{\mathrm{S} 1}$ & 0.981 & 0.983 & 0.985 & 0.987 & 0.989 \\
\hline & & $\mathrm{V}_{\mathrm{S} 2}$ & 1.750 & 1.811 & 1.872 & 1.930 & 1.987 \\
\hline
\end{tabular}

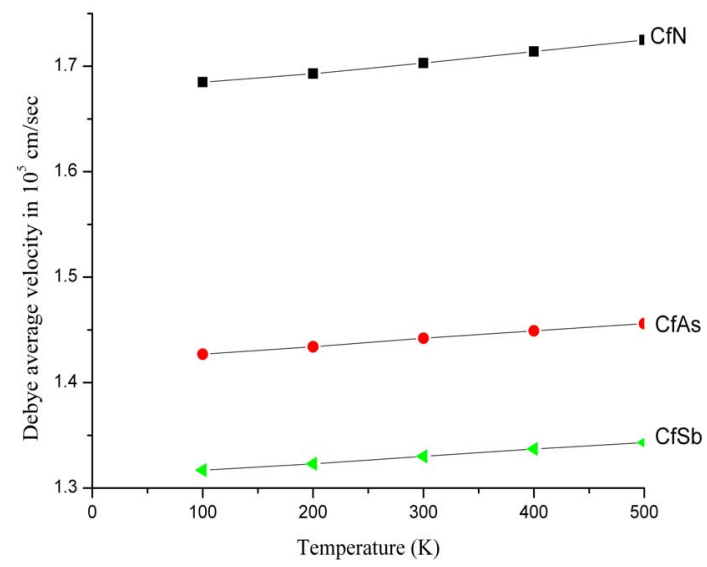

Figure 1. Debye average velocity versus temperature along $<100>$ direction.

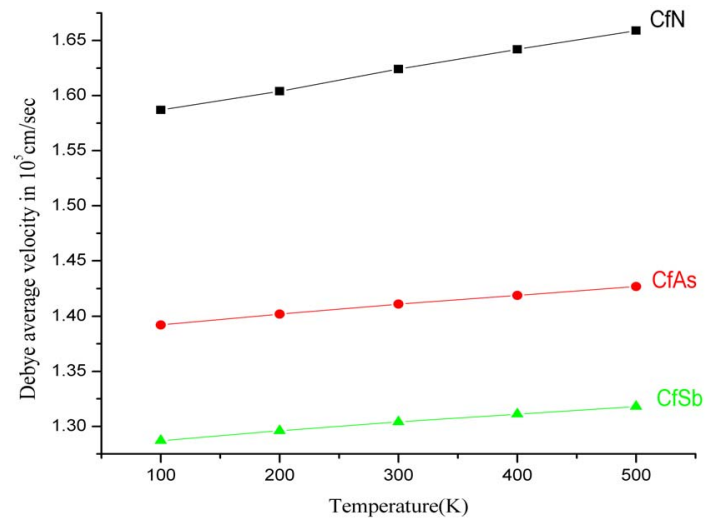

Figure 2. Debye velocity versus temperature along $<110>$ direction.

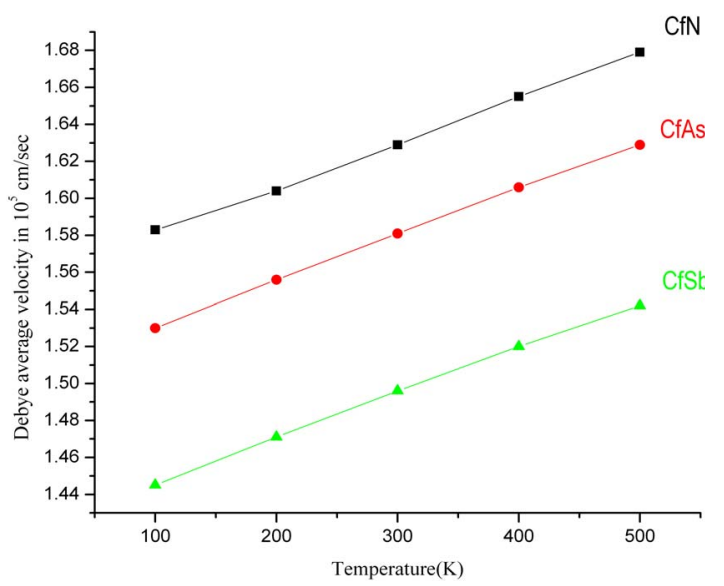

Figure 3. Debye average velocity versus temperature along $<111>$ direction.

direction over 20 modes and for shear wave polarized along $<110>$ direction over 18 modes and for shear wave polarized along $<110>$ direction over 26 modes. The temperature dependent averaged ultrasonic Grüneisen parameters and averaged squares of the Grüneisen parameters are presented in Table 4.

The values of average Grüneisen parameters and averaged squares of the Grüneisen parameters are the highest for $\mathrm{CfSb}$ and lowest for $\mathrm{CfN}$ along $<110>$ direction for longitudinal waves and shear as shown in Table 4. It is obvious from Table 4, that CfSb is better for thermal purposes for longitudinal wave propagation along $<110>$ direction and $\mathrm{CfN}$ would be better for shear wave propagation. It is found that obtained values of Grüneisen 
Table 4. Ultrasonic Grüneisen parameters of $\mathrm{CfY}$ along different crystallographic directions in the temperature range $100 \mathrm{~K}$ $-500 \mathrm{~K}$.

\begin{tabular}{|c|c|c|c|c|c|c|}
\hline Material & Grüneisen parameters & $100 \mathrm{~K}$ & $200 \mathrm{~K}$ & $300 \mathrm{~K}$ & $400 \mathrm{~K}$ & $500 \mathrm{~K}$ \\
\hline \multicolumn{7}{|c|}{ Ultrasonic longitudinal wave propagates along $<100>$} \\
\hline \multirow[t]{2}{*}{$\mathrm{CfN}$} & $<\gamma_{\mathrm{i}}^{\mathrm{j}}>$ & 0.472 & 0.455 & 0.437 & 0.421 & 0.406 \\
\hline & $<\left(\gamma_{i}{ }^{j}\right)^{2}>$ & 1.690 & 1.586 & 1.482 & 1.388 & 1.304 \\
\hline CfAs & $<\gamma_{\mathrm{i}}^{\mathrm{j}}>$ & 0.458 & 0.438 & 0.417 & 0.403 & 0.388 \\
\hline \multirow{3}{*}{$\mathrm{CfSb}$} & $<\left(\gamma_{i}{ }^{j}\right)^{2}>$ & 2.030 & 1.896 & 1.763 & 1.673 & 1.580 \\
\hline & $<\gamma_{i}{ }^{j}>$ & 0.457 & 0.436 & 0.417 & 0.400 & 0.384 \\
\hline & $<\left(\gamma_{\mathrm{i}}{ }^{\mathrm{j}}\right)^{2}>$ & 2.114 & 1.969 & 1.842 & 1.731 & 1.634 \\
\hline \multicolumn{7}{|c|}{ Ultrasonic shear wave propagates along $<100>$ and polarized along $<100>$ direction } \\
\hline $\mathrm{CfN}$ & $<\left(\gamma_{i}^{j}\right)^{2}>$ & 0.130 & 0.127 & 0.123 & 0.120 & 0.118 \\
\hline CfAs & $<\left(\gamma_{i}{ }^{j}\right)^{2}>$ & 0.119 & 0.118 & 0.117 & 0.116 & 0.115 \\
\hline $\mathrm{CfSb}$ & $<\left(\gamma_{i}{ }^{j}\right)^{2}>$ & 0.120 & 0.119 & 0.118 & 0.117 & 0.117 \\
\hline \multicolumn{7}{|c|}{ Ultrasonic longitudinal wave propagates along $<111>$} \\
\hline \multirow{2}{*}{$\mathrm{CfN}$} & $<\gamma_{\mathrm{i}}^{\mathrm{j}}>$ & -0.687 & -0.655 & -0.622 & -0.592 & -0.565 \\
\hline & $<\left(\gamma_{i}{ }^{j}\right)^{2}>$ & 2.205 & 2.010 & 1.826 & 1.665 & 1.527 \\
\hline \multirow{2}{*}{ CfAs } & $<\gamma_{\mathrm{i}}^{\mathrm{j}}>$ & -0.720 & -0.682 & -0.644 & -0.617 & -0.589 \\
\hline & $<\left(\gamma_{i}{ }^{j}\right)^{2}>$ & 2.333 & 2.100 & 1.881 & 1.730 & 1.584 \\
\hline \multirow{2}{*}{$\mathrm{CfSb}$} & $<\gamma_{\mathrm{i}}^{\mathrm{j}}>$ & -0.728 & -0.688 & -0.652 & -0.620 & -0.591 \\
\hline & $<\left(\gamma_{i}{ }^{j}\right)^{2}>$ & 2.392 & 2.140 & 1.927 & 1.748 & 1.595 \\
\hline \multicolumn{7}{|c|}{ Ultrasonic shear wave propagates along $<110>$ and polarized along $<110>$ direction } \\
\hline $\mathrm{CfN}$ & $<\left(\gamma_{i}\right)^{j}>$ & 1.734 & 1.670 & 1.602 & 1.539 & 1.482 \\
\hline CfAs & $<\left(\gamma_{\mathrm{i}}^{\mathrm{j}}\right)^{2}>$ & 2.348 & 2.247 & 2.141 & 2.074 & 2.001 \\
\hline $\mathrm{CfSb}$ & $<\left(\gamma_{\mathrm{i}}^{\mathrm{j}}\right)^{2}>$ & 2.470 & 2.360 & 2.262 & 2.176 & 2.101 \\
\hline \multicolumn{7}{|c|}{ Ultrasonic longitudinal wave propagates along $<110>$} \\
\hline \multirow[t]{2}{*}{$\mathrm{CfN}$} & $<\gamma_{\mathrm{i}}^{\mathrm{j}}>$ & -0.796 & -0.767 & -0.737 & -0.708 & -0.681 \\
\hline & $<\left(\gamma_{i}{ }^{j}\right)^{2}>$ & 2.318 & 2.141 & 1.969 & 1.818 & 1.688 \\
\hline \multirow[t]{2}{*}{ CfAs } & $\left\langle\gamma_{\mathrm{i}}^{\mathrm{j}}\right\rangle$ & -0.768 & -0.733 & -0.695 & -0.670 & -0.642 \\
\hline & $<\left(\gamma_{\mathrm{i}}{ }^{\mathrm{j}}\right)^{2}>$ & 2.551 & 2.362 & 2.180 & 2.056 & 1.933 \\
\hline \multirow{2}{*}{$\mathrm{CfSb}$} & $<\gamma_{\mathrm{i}}^{\mathrm{j}}>$ & -0.766 & -0.728 & -0.693 & -0.661 & -0.632 \\
\hline & $<\left(\gamma_{i}{ }^{j}\right)^{2}>$ & 2.646 & 2.444 & 2.272 & 2.124 & 1.997 \\
\hline \multicolumn{7}{|c|}{ Ultrasonic shear wave propagates along $<110>$ and polarized along $<001>$ direction } \\
\hline $\mathrm{CfN}$ & $<\left(\gamma_{\mathrm{i}}^{\mathrm{j}}\right)^{2}>$ & 0.154 & 0.149 & 0.143 & 0.138 & 0.133 \\
\hline CfAs & $<\left(\gamma_{i}{ }^{j}\right)^{2}>$ & 0.103 & 0.101 & 0.097 & 0.0961 & 0.093 \\
\hline $\mathrm{CfSb}$ & $<\left(\gamma_{i}{ }^{j}\right)^{2}>$ & 0.099 & 0.097 & 0.094 & 0.092 & 0.090 \\
\hline \multicolumn{7}{|c|}{ Ultrasonic shear wave propagates along $<110>$ and polarized along direction $<1 \overline{1} 0>$} \\
\hline $\mathrm{CfN}$ & $<\left(\gamma_{\mathrm{i}}\right)^{\mathrm{j}}{ }^{2}>$ & 2.524 & 2.428 & 2.325 & 2.227 & 2.136 \\
\hline CfAs & $<\left(\gamma_{i}{ }^{j}\right)^{2}>$ & 3.471 & 3.306 & 3.132 & 3.020 & 2.899 \\
\hline $\mathrm{CfSb}$ & $<\left(\gamma_{i}{ }^{j}\right)^{2}>$ & 3.659 & 3.478 & 3.317 & 3.173 & 3.046 \\
\hline
\end{tabular}

parameters and average squares of the Grüneisen parameters are decreasing with increase in the temperature. This is due to adjustment of SOEC and TOEC for different modes. This type of nature is also found in other B1 structured materials like rare-earth monopnictides $[21,22]$, semiconductors [23] and rare-earth monochalcogenides [24,25].

\section{Conclusions}

On the basis of analysis of the above results, we can say that

- Evaluated values of SOEC and TOEC have been compared with available same type B1 structured mate- 
rials, which are in agreement; hence our approach to compute elastic constants is justified.

- SOEC and TOEC of CfN are highest so mechanical properties will be better than other CfY.

- All the chosen materials follow the Born criterion of stability. So they all are stable.

- SOEC and TOEC have been used to find out the ultrasonic velocities for longitudinal and shear waves, Debye average velocity and Grüneisen parameters in CfY.

- Ultrasonic velocity is found to be the highest for CfAs along all chosen directions, so CfAs will be the most suitable compound for wave propagation.

- $\mathrm{CfSb}$ is better for longitudinal wave propagation along $<110>$ direction and $\mathrm{CfN}$ would be better for thermal purposes, because Grüneisen parameters are the most sensitive to temperature.

Hence, we conclude that current approach is justified and obtained results will be useful for finding various theoretical, experimental investigations like ultrasonic attenuation, non-linearity parameters, ultrasonic measurements, polarizing microscopy, solid state NMR, SEM, TEM.

\section{Acknowledgements}

The authors are thankful to Prof. Dr. R.R. Yadav, Department of Physics, University of Allahabad for his stimulating discussion and encouragement for the work.

\section{References}

[1] A.K. Pandey, B.K. Pandey and Rahul, "Theoretical prediction of Grüneisen parameters for bulk metallic glasses", Journal of Alloys and Compounds, Vol. 509, No.11, 2011, pp. 4191-4197.

[2] V.P. Singh and M.P. Hemkar, "Dynamical theory for Grüneisen parameters in fcc metals", Journal of Physics F and Metal Physics, Vol. 7, No. 5, 1977, pp. 761-769.

[3] D.N. Joharpurkar and M.A. Breazeale, "Nonlinearity parameters, nonlinearity constant and frequency dependence of ultrasonic attenuation in GaAs", Journal of Applied Physics, Vol. 67, No. 1, 1999, pp. 76-80.

[4] D. Singh, D.K. Pandey, D.K. Singh and R.R. Yadav, "Propagation of ultrasonic waves in neptunium monochalcogenides", Applied Acoustics, Vol.72, No. 10, 2011,

[5] R.G. Haire and R.D. Gand Baybarz, "Crystal structure and melting point of metal", Journal of Inorganic and Nuclear Chemistry, Vol. 36, No. 6, 1974, pp. 1295-1302.

[6] D. Damien, R.G. Haire and J.R. Peterson, "Cf-249 monoarsenide and monoantimonide", Inorganic and Nuclear Chemistry Letters, Vol. 16, No. 9-12, 1980, pp.537-41.
[7] S.E. Nave, J.R. Moore, M. T. Spaar, R.G. Haire and P.G. Huray, "Magnetic susceptibility of Cf oxides", Physica B, Vol. 130, No. 1-3, 1985, pp. 225-227.

[8] S.E. Nave, J. R Moore, R.G Haire, J.R Peterson, D.A. Damien and P.G Huray, "Magnetic susceptibility of CfN, CfAs and CfSb", Journal of Less Common Metals, Vol. 121, 1986, pp. 319-24.

[9] M. Born and J. E. Mayer, "Zur Gittertheorie der Ionenkristalle”, Zeitschrift für Physik, Vol. 75, No. 1-21931, pp. $1-18$.

[10] K. Brugger, "Thermodynamic definition of higher elastic coefficients", Physical Review, Vol. 133, No. 6A, 1964, pp. A1611-A1612.

[11] G. Leibfried and H. Haln, "Zur temperaturabhangigkeit der elastischen konstantaaen von al-halihalogenidkristallen", Zeitschrift für Physik, Vol. 150, 1958, pp. 497525.

[12] G. Leibfried and W. Ludwig, "Theory of anharmonic effect in crystal", Solid State Physics XII, in: F. Seitz, D. Turnbull (Eds.). Academic Press, New York 1961, pp. 276-444

[13] S. Mori and Y. Hiki, "Calculations of third order elastic constants and forth order elastic constants of alkali halides crystals", Journal of Physical Society of Japan, Vol. 45, 1978, pp. 1449-1456.

[14] R.W.F. Wyckoff, Crystal Structure, Interscience Publication, New York, 1963.

[15] D. Singh, Rajkumar, D.K. Pandey, "Temperature and orientation dependence of ultrasonic parameters in americium monopnictides", Advances in Materials Physics and Chemistry, Vol.1, No. 2, 2011, pp. 31-38.

[16] R. Nava and J. Romero, "Ultrasonic Grüneisen parameters for non conducting cubic crystals", Journal of Acoustical Society of America, Vol. 64, No. 2, 1978, pp. 529532.

[17] K. Brugger, "Generalized Grüneisen parameters in anisotropic Debye model", Physical Review, Vol. 137, No. 6A, 1965, pp. A1826-A1827.

[18] S.D. Lambade, G.G. Sahasrabudhe and S. Rajagopalan, "Temperature dependence of acoustic attenuation in silicon”, Physical Review B, Vol. 51, No. 22, 1995, pp 15861-158866.

[19] W.P. Mason, "Effect of impurities and phonon processes on the ultrasonic attenuation in germanium crystal quartz and silicon", Physical Acous-tics IIIB, Academic Press, New York, 1965, pp. 237-285.

[20] M.P. Tosi, Cohesion of ionic solids in Born model, in: Solid State Physics, Vol.16, F. Seitz, D. Turnbull (Eds.), (Academic Press, New York, 1964) pp. 1-120.

[21] D. Singh, S. Tripathi, D.K. Pandey, A.K. Gupta, D.K. Singh and J. Kumar, "Ultrasonic wave propagation in semimetallic single crystals", Modern Physics Letters B, Vol. 25, No. 31, 2011, pp. 2377-2390.

[22] R.R. Yadav, A.K. Tiwari and D. Singh, "Effect of pressure on ultrasonic attenuation in Ce-monopnictides at low 
temperature", Journal of Materials Science, vol. 40, No. 19, 2005, pp. 5319-5321.

[23] D. Singh, R.R. Yadav and A.K. Tiwari, "Ultrasonic attenuation in semiconductors", Indian Journal of Pure and Applied Physics, Vol. 40, No. 12, 2002, pp. 845-849.

[24] D. Singh, D.K. Pandey and P.K. Yadawa, "Ultra-sonic wave propagation in rare-earth monochalcogenides",
Central European Journal of Physics, Vol. 7, No. 1, 2009, pp. 198-205.

[25] R.R. Yadav and D. Singh, "Effect of thermal con-ductivity on ultrasonic attenuation in praseodymium monochalcogenides", Acoustical Physics, Vol. 49, No. 5, 2005, pp. 595-604. 